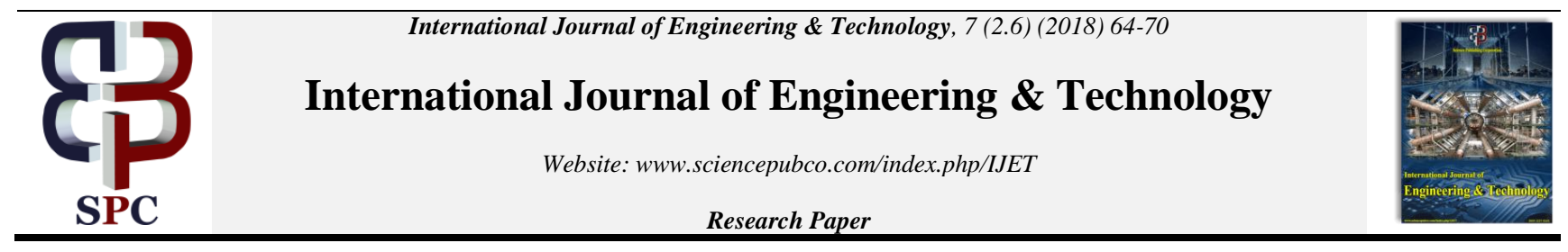

\title{
A survey on exchange rate prediction using neural network based methods
}

\author{
Pragyan Paramita Barik ${ }^{1 *}$, Smruti Rekha Das ${ }^{2}$, Debahuti Mishra ${ }^{3}$ \\ ${ }^{1}$ Department of Computer Science and Information Technology, Siksha 'O' Anusandhan Deemed to be University, Odisha, INDIA \\ ${ }^{2}$ Department of Computer Science and Engineering, Siksha 'O' Anusandhan Deemed to be University, Odisha, INDIA \\ ${ }^{3}$ Department of Computer Science and Engineering, Siksha 'O' Anusandhan Deemed to be University, Odisha, INDIA \\ *Corresponding author E-mail: pragyan.barik.pb@gmail.com
}

\begin{abstract}
Forecasting exchange rate has always been in demand as it is very important for the international traders to predict how their money will perform against other currencies. So different methods have been applied by the researchers to accurately predict the exchange rates so that it can assist in taking decision while trading. From all the models the Artificial Neural Network (ANN) has given consistent performance in prediction by overcoming the limitations of other models and has outperformed all the models in terms of efficiency. The evolution of ANN is remarkable. In this paper, we have given the performance of different network models used by researchers to predict the exchange rates of major currencies in the future.
\end{abstract}

Keywords: Artificial Neural Network (ANN); Currencies; exchange rate; forecasting; outperformed.

\section{Introduction}

The existence of foreign exchange (FOREX or FX) has been seen ever since people traded foods, commodities, and livestock with different currencies. The massive increase in the foreign transaction is the result of increasing globalization. FOREX is the price of domestic currency in terms of foreign currency. FOREX rate refers the rate at which one country's currency is exchanged with another country's currency. It measures the number of units of one currency required to exchange with a number of units of other currency. The FOREX market of any country is an essential component of the monetary system. It is the place where the currency of one country is traded for the currency of another country. It is "over the counter" market where currencies are traded virtually around the globe. New York, Singapore, London, and Tokyo are the largest trading hubs [1] in the world. FOREX market [2] is the largest financial market where on an average \$5.09 trillion is traded daily as calculated in April 2016.

The most commonly traded currency pairs [3] are US Dollar (USD)/Japanese Yen (JPY), Euro (EUR)/USD, USD/Confederazione Helvetica (Swiss) Franc (CHF), Australian Dollar (AUD)/USD, EUR/JPY and Great Britain Pound (GBP)/USD).The traders in the FOREX market are the central banks, commercial companies, institutional investors, governments and financial institutions. Main participants in the FOREX market are the international banks. These financial institutions act as the trading center for different types of buyers and sellers. The FOREX market [2] uniqueness can be described through its huge trading volumes, large asset class leading to liquidity, small margins of relative profit and use of leverage to increase profit and loss margins. Modern FOREX market began during the 1970s after World War II. The following three decades saw government restriction on FOREX transaction under the Bretton Woods sys- tem. Hence countries switched to floating exchange rates from fixed exchange rate regime.

Since 1973 with the collapse of Bretton Woods, prediction of FOREX rate has become an emergent topic of research. In 1983, Meese et al. [4] observed that prediction through different structural models which were based on asset theories of FOREX rate and monetary did not perform better than the simple random walk model. In 1987, Alexander et al. [5] found econometric models were outperformed even after time-varying parameters are used in the models. There are many factors that affect the FOREX rates such as correlated micro and macro-economic, inflation, the rate of interest, cost of manufacture, debt, politics, and psychology. Predicting FOREX rate is the most challenging task in today's world due to its intrinsic difficulty and practical applications. Efficient Market Hypothesis given by Eugene Fama states that asset price fully reflects the available information. Among three variants [6] of the hypothesis, weak form alleged that present asset price depicts all information of the past. Then Random Walk model was formulated. From practical and theoretical standpoints [7] the suitability of this model was criticized. A number of studies indicate that various techniques have been applied to predict the FOREX rate and estimate its volatility. The efficiency of exchange rate market [8] makes it troublesome to make long-term and short-term forecasting. Initially, parametric models were used for forecasting which used economic theory to explain the relationship between exchange rate and different variables. Then econometric models were developed with time-varying parameters which were found to be outperformed by the random walk model because econometric models were linear and used under the specific assumption. Autoregressive Integrated Moving Average model(ARIMA) is a generalization of Autoregressive Moving Average Model (ARMA). The ARIMA model is an econometric model that uses a linear relationship between the present value of the latent variable and preceding value. Time series data is used in ARIMA model to better predict the future values. The failure be- 
hind time series models is it is highly nonlinear. The variance and mean of the series vary over time. Engle [9] and Bollerslev [10] introduced Autoregressive Conditional Heteroscedasticity (ARCH) models to overcome the problem of high nonlinearity of time series model. Then ARCH models were improvised with a different implementation. In the last few decades with the emergent of different techniques in Artificial Intelligence and high computational power of computers, the non-parametric models like ANN and Support Vector Machine (SVM) are widely used.

Since now many researchers have proposed new models or an improvised version of existing model to increase the accuracy of the prediction. According to present-day researchers, linear models like Hidden Markov Model (HMM), Generalized Linear Autoregression and ARIMA Model could not capture the nonlinear relationship. Financial time series data are inconsistent, noisy, chaotic and non-stationary and as we know that historical data has a major role in determining the future prediction so because of complexity, noise and volatility ANN is widely used for prediction. Different techniques in Neural Networks were developed to increase the accuracy level like Back Propagation Neural Network (BPNN), Functional Link Artificial Neural Network (FLANN), Radial Basis Function Neural Network (RBFNN), Recurrent Neural Network (RNN) etc.

The paper is further organized as follows: Firstly, we have discussed the advantages of using neural network techniques and its application in various fields. Then we have analyzed the different neural network techniques used by researchers to predict the FOREX rates. Lastly, we have concluded whether neural network techniques have given better prediction result compared to traditional techniques.

\section{Literature Survey}

\subsection{ANN}

The growing popularity of ANN is due to its ability to handle complex data. ANN appears to be a recent development but it has been developed before the invention of computers. Now due to growth in computational power of computers and advancement in technology ANN is used in various fields like medicine for modeling and diagnosing the cardiovascular diseases, diagnosis of hepatitis, electronic noses-detection, and reconstruction of odors, business for sales forecasting, marketing, credit evaluation etc. Examples of some more specific paradigms are undersea mining, texture analysis, hand-written word recognition and facial recognition. ANN is inspired by the working principle of the human neuron. The first neuron was developed by McCulloch in the year 1943. The use of neural networks grew because of its capability to derive meaningful information from imprecise data, extract patterns and detect trends that were impossible for human because of complexity in data. Other advantages are its adaptive feature which means it has the ability to do task based on the training given, self-organization, real-time operation, and fault tolerant. The ability to create its own organization based on the training received is called self- organization. The neural network is an interconnected network of processing elements or nodes called neurons. A simple Neuron consists of the input layer, neuron, and an output layer. Neuron learns through training. After training, they are tested by giving a new set of data. Neural Network Regression (NNR) models have proven to be an alternative to linear and traditional methods. Refenes et al. in 1993 used the period 1984-1992 and developed a neural network hybrid model which concluded that neural network is superior to traditional models. But Tyree et al. [11] in 1995 found random walk model to be more effective than NNR models. Later on, Shazly et al. [12] in 1997 compared the forward rate of GBP, Deutschmark (DEM) and JPY against a common currency using weekly data from 19881994. They found that neural networks beat the forward rate both in terms of accuracy and correctness. To evaluate the models on the basis of the correctness of sign and trading performance Yao et al. [13] in 1996 forecasted the exchange rates of GBP, DEM, JPY, CHF, AUD against USD from 1984-1995 using weekly data. They confirmed that NNR models give higher correctness of assign and consequently give higher returns. Dunis et al. [14] in 2002 determined that NNR models do add value to the forecasting process. They took daily data from 17 October 1994 to 18 may 2000 for insample estimation and from 19 May 2000 to 3 July 2001 for outof-sample forecasting of EUP/USD exchange rates which clearly showed that NNR models confirm the potential of accurate forecasting. Lisi et al. [7] have compared the performance of neural networks and chaotic models over common data sets and variables. It is an attempt to verify whether they can predict better under the same experimental condition. The monthly exchange rates of four major European currencies (DEM, Italian Lira French Franc, and GBP) are taken for the study against American Dollar from 1973 to 1995 . The prediction performance is determined by Normalized Mean Square Error (NMSE). The results show that both models perform better than random walk model and neural network perform slightly better than the chaotic model. In 2004 a hybrid model for predicting exchange rate was developed [8] which involves two stages. Here parametric techniques like vector autoregressive (VAR), ARIMA and co-integration techniques are used with nonparametric techniques like support vector regression (SVR) and ANN which exhibited that input selection is very important. ARIMA with co-integration analysis was used for input selection process and after a number of inputs were determined ANN and SVR are applied. Time series technique uses the different assumption of data. So estimation and forecasting are based on assumptions. This two-stage hybrid model was developed to overcome this drawback. Philip et al. [15] used ANN for FOREX prediction with the consideration of existing HMM to correct some of the problems like uncertainty and instability nature of FOREX data. The model was designed in two phases: training and forecasting. Back-propagation was used for training and to learn the model how to approximate. Multilayer Perceptron Network (MLP) was used for prediction. The datasets were taken from oanda website. FOREX rate of major currencies like USD, EUR, GBP and YEN, was forecasted against Nigerian Money (Naira). It is observed that the ANN model outperformed HMM. In recent years researchers are using hybrid model and ensemble models to combine the features of all computational intelligent methods to enhance the prediction accuracy. Ravi et al. [16] have proposed an ensemble model using BPNN, Wavelet neural network, Multivariate adaptive regression splines, SVR, Dynamic evolving Neuro-fuzzy inference system, Group method of Data handling (GMDH) and Genetic programming (GP). USD is forecasted with respect to DEM, YPY, and GBP. The performance of all methods is compared with NMSE and directional statistics. GMDH and GP yielded best results overall currencies. Dunis et al. [17] in 2010 evaluated daily data from 2000-2009 in which the period from 20072009 (financial crisis period) was taken as out-of-sample testing. The aim was to check whether neural network models are still superior to all another model for forecasting EUR/USD exchange rates. MLP, RNN and Higher Order Neural Network are compared against a random walk and ARMA model. The result showed that still, neural networks remained superior to traditional methods. Recent works in forecasting exchange involve accuracy in prediction. Erdogan et al. [18] have EURO and Turkish Lira (TRY) exchange rates. For accurate prediction, ANN with backpropagation is used. The accuracy of neural networks is affected by several factors. To acquire higher performance the number of neurons were changed and seen, transfer function and learning algorithms were changed. The results obtained were compared with mean squared error and found that forecast values were very close to the original ones. Researchers are experimenting ANN with different techniques to get an accurate result. Lima et al. in [19] have used ANN and hybrid Neuro-Fuzzy system (ANFIS) to forecast the future rate of the FOREX market. They have used MLP to forecast the fluctuation of the exchange rate and ANFIS model is used to predict the exchange rate of USD/INR for next day. The model forecasts the trend of the FOREX market and the 
exchange rate for the next day with high accuracy. Further, a model can be developed to combine the output of ANN with the input of ANFIS to make prediction more accurate. Svitlana Galeshchuk in 2015 [20] used daily, monthly and quarterly exchange rates of USD/JPY, EUR/USD and GBP/USD. The results obtained show that short-term forecasting method used for prediction gives better accuracy and the method can be used in forecasting time series data using neural networks.

Researchers [21-24] have proposed different ANN models to forecast the currency exchange rates and have concluded that the proposed models have outperformed the conventional model taken for comparison. (Table 1)

Table 1: Findings of the model using ANN technique

\begin{tabular}{|c|c|c|c|}
\hline Authors & Currency used & Models used & Findings \\
\hline $\begin{array}{c}\text { Ashok } \\
\text { K.Nag } \text { et } \\
\text { al. }\end{array}$ & $\begin{array}{c}\text { DEM/USD } \\
\text { YEN/USDUSD/ } \\
\text { GBP }\end{array}$ & $\begin{array}{c}\text { ANN }+ \\
\text { GA }\end{array}$ & $\begin{array}{c}\text { Proposed model } \\
\text { outperforms nonlin- } \\
\text { ear statistical models } \\
\text { like ARCH and its } \\
\text { types }\end{array}$ \\
\hline $\begin{array}{c}\text { He Ni } \text { et } \\
\text { al. }\end{array}$ & USD/GBP & $\begin{array}{c}\text { Hybrid model } \\
\text { (RSOM + } \\
\text { SVR + GA ) }\end{array}$ & $\begin{array}{c}\text { Model results are } \\
\text { improved over } \\
\text { GARCH }\end{array}$ \\
\hline $\begin{array}{c}\text { Chakra- } \\
\text { dara } \\
\text { panda } t \\
\text { al. }\end{array}$ & INR/USD & ANN & $\begin{array}{c}\text { ANN beats linear } \\
\text { autoregression and } \\
\text { random walk }\end{array}$ \\
\hline $\begin{array}{c}\text { Gioqinan } \\
\text { g Zhang } \\
\text { et al. }\end{array}$ & GBP/USD & ANN & $\begin{array}{c}\text { Input and architec- } \\
\text { ture selection is } \\
\text { important }\end{array}$ \\
\hline
\end{tabular}

\subsection{BPNN}

ANN is an effective model for forecasting because of its capability to approximate a continuous function to any desired accuracy. It is important to determine an appropriate network structure so that the function can be approximated well. A single layer network cannot approximate well and the complex network can overfit the data. Multilayer feedforward network is commonly used. A multilayer feed-forward network has many hidden layers between input and out layer. It can solve the more complicated problem. Training a multilayer network is difficult. BPNN was first proposed by Rumelhart and McClelland in the year 1985. ANN can be designed in two ways: feed-forward or feedback. Back-propagation networks are the type of feedback network where inputs are taken from the preceding layer and output is given to the next layer. It consists of the input layer, hidden layers, and an output layer. If the desired output does not match with the actual output then weights are readjusted to lessen the difference. The process continues until the error is less than the desired limit. The hidden layer in BPNN plays an important role in BPNN. It empowers the ANN to extract patterns and generalize. If the hidden layer is large then it can bereave the network of its generalizing ability when the network starts memorizing and if is small then it can reduce the accuracy of recall. Carney et al. [25] predicted exchange rates of DEM, GBP, Swedish krona, and USD. He suggested that neural networks perform better than conventional models. Kamruzzaman et al. [26] proposed an ANN-based model to predict the exchange rate of six foreign currencies against the Australian dollar (AUD). They used three learning algorithms: Scaled Conjugate Gradient (SCG), Standard Back Propagation and Back-propagation with Bayesian Regularization. All models outperformed ARIMA model and SCG based model performed the best. In 2012 Suresh Kumar Sharma et al. [27] have used BPNN to predict USD/INR exchange rates where the input to the neural network is moving an average of USD/INR. The results show that ANN is a good forecaster in exchange rate prediction. According to Meng et al. [28], a majority of researchers have focused on forecasting. It becomes a difficult task for others to make a trading decision. Therefore, they have developed an automated trading system based on BPNN. Exchange rate prediction was done with a single hidden layer feed forward network. Then based on prediction results trading rules were formulated and parameters were optimized based on the profitability performed on EUR/USD and GBP/ USD separately. The system is trained and tested and it showed that the BPNN Expert Advisor can successfully get consistent profit for a limited time. Lavanya et al. [29] have used various Back-Propagation algorithms like Resilient Back Propagation, Variable Learning Rate Back Propagation, Fletcher-Powell Conjugate Gradient, Polak-Ribiere Conjugate Gradient, with Powell/Beale restarts, SCG, BFGS Quasi-Newton, One Step Secant and Levenberg-Marquardt (LM). LM based algorithm predicted the exchange rates between AUD/YEN more accurately than other algorithms. Chandar et al. [30] in 2015 have applied five different ANN based learning algorithms: Batch gradient descent with momentum, Batch gradient descent, Variable Learning Rate Back-propagation, Resilient Back-propagation and LM for predicting FOREX rates of INR against four currencies: PS, USD, EURO, and JPY. The results show that LM forecasts more accurately. Thakur et al. [31] in the year 2015 examined the data between January 2000 and December 2012 to predict the inflation of India using a prediction model based on feed forward back propagation neural network (FBNN) model. The results were compared with other forecasting agencies and found that proposed model gives almost accurate prediction. Similarly Murthy in 2016 [32] used FBNN model with gradient descent approach using LM algorithm to predict the daily exchange rate of USD/INR and compared the results against MSE, Mean Absolute Error, Directional Accuracy. From the results it was concluded that neural networks gave good prediction during the crisis period. Then in 2017 Chen et al. [33] forecasted the exchange rates of USD/INR during the inflation period using FBNN model from January 2001 to December 2014 and compared with actual forecasted value. After that they used the model to forecast the exchange rates for the year 2015 and it proved to be the most accurate and effective model.

Researchers [34-37] have proposed models using BPNN technique to increase the prediction accuracy of different currencies exchange rates and found that the models perform better when trained with Back-Propagation algorithms. (Table 2)

Table 2: Findings of the model using BPNN technique

\begin{tabular}{|c|c|c|c|}
\hline Authors & $\begin{array}{c}\text { Currency } \\
\text { used }\end{array}$ & Models used & Findings \\
\hline Sun Ye & RMB & BPNN & $\begin{array}{l}\text { BPNN forecast } \\
\text { is precise and } \\
\text { efficient and } \\
\text { RMB will ap- } \\
\text { preciate in } \\
\text { future }\end{array}$ \\
\hline $\begin{array}{l}\text { Rudra P. } \\
\text { Pradhan } \\
\text { et al. }\end{array}$ & $\begin{array}{l}\text { INR against } \\
\text { GBP, EURO, } \\
\text { JPY(Daily } \\
\text { and monthly }\end{array}$ & $\begin{array}{c}\text { Feed Forward } \\
\text { BPNN }\end{array}$ & $\begin{array}{c}\text { Proposed model } \\
\text { predicts accu- } \\
\text { rately } \\
\text { both daily and } \\
\text { monthly data } \\
\end{array}$ \\
\hline Yu et al. & $\begin{array}{c}\text { EUR/USD } \\
\text { and JPY/USD }\end{array}$ & $\begin{array}{c}\text { Exponential } \\
\text { Smoothing + BPNN }\end{array}$ & $\begin{array}{c}\text { Hybrid model } \\
\text { performs better } \\
\text { than individual } \\
\text { models }\end{array}$ \\
\hline $\begin{array}{l}\text { Chandar } \\
\text { et al. }\end{array}$ & $\begin{array}{l}\text { INR against } \\
\text { PS, USD, } \\
\text { EURO, and } \\
\text { JPY }\end{array}$ & $\begin{array}{l}\text { BPNN (trained with } \\
\text { variable learning } \\
\text { rate Back Propaga- } \\
\text { tion, Batch gradient } \\
\text { descent, resilient } \\
\text { Back Propagation,) }\end{array}$ & $\begin{array}{l}\text { Resilient Back } \\
\text { Propagation } \\
\text { gives closer } \\
\text { prediction for } \\
\text { all four curren- } \\
\text { cies }\end{array}$ \\
\hline
\end{tabular}

\subsection{FLANN}

In the recent days, forecasting the financial market is tedious work and it has been observed that there is a lot of improvement in exchange rate prediction. It is evident from the study of existing models that many evolutionary techniques have been applied for this. The use of Multilayer ANN (MLANN) can be seen very often. But it involves certain issues which led to the development of FLANN based models. The first issue is MLANN involves more computation. Second issue [38] is the accuracy of existing tech- 
niques. Therefore FLANN was developed as it is simple, efficient has less computation and better forecasting ability. FLANN is a single layer neural network with nonlinear input and single neuron at the output, first proposed by Pao [39] in 1989. In compared to MLANN this network structure is simple and involves fewer computations. Each input in the FLANN network undergoes functional expansion. In the functional block, a nonlinear input is generated which causes the input vector to increase dimensionally Introducing nonlinearity to the input helps to reduce the computational load. Majhi et al. [38] keeping in view the accuracy, less number of computation, and fast forecasting, developed an efficient and low complexity forecasting model for exchange rate prediction. They have developed two nonlinear adaptive models: FLANN and cascaded FLANN (CFLANN). They have used both the models to forecast the exchange rate between USD and three other currencies: GBP, INR, and JPY. The prediction is done one, three, six and twelve months ahead and the results of two models have been compared with Least Mean Square (LMS) model. It is observed that CFLANN outperformed FLANN and LMS models. Researchers are more focusing on accuracy. Thus a lot of optimization techniques are being used like CRO which is based on the nature of chemical reactions. Sahu et al. [40] have used CRO based forecasting model to predict exchange rates of USD against INR, JPY, and EURO. Two different techniques have been compared such as FLANN with LMS and CRO based FLANN with LMS. It was observed that CRO based FLANN produced a better result. FLANN model was seen in stock price prediction when Patra et al. [41] developed a FLANN based prediction system. The use of FLANN model can be widely seen in forecasting of the financial market. Anish et al. [42] have used FLANN based technique for predicting net asset value (NAV). Researchers in NAV prediction show that there is a need for efficient forecasting model that involves less computation as MLANN and GA they are very time-consuming. Thus the authors have used FLANN model to dig out patterns hidden in the mutual funds. Performance is evaluated an using RMSE, Mean absolute percentage error and MSE. It is concluded that FLANN shows better results.

Different hybrid models have been implemented using FLANN model by researchers [43-46] and the proposed models have predicted the exchange rates of various currencies accurately. (Table 3)

Table 3: Findings of the model using FLANN technique

\begin{tabular}{|c|c|c|c|}
\hline Authors & $\begin{array}{c}\text { Currency } \\
\text { used }\end{array}$ & Models used & Findings \\
\hline Hua et al. & $\begin{array}{c}\text { USD } \\
\text { against } \\
\text { GBP, INR, } \\
\text { JPY }\end{array}$ & $\begin{array}{c}\text { Hybrid } \\
\text { model } \\
(\text { FLANN+KR) }\end{array}$ & $\begin{array}{l}\text { FLANN-KR model } \\
\text { outperformed Adap- } \\
\text { tive Exponential } \\
\text { Smoothing method } \\
\text { and FLANN model }\end{array}$ \\
\hline $\begin{array}{c}\text { Jena } e t \\
\text { al. }\end{array}$ & $\begin{array}{l}\text { USD to } \\
\text { GBP and } \\
\text { INR }\end{array}$ & 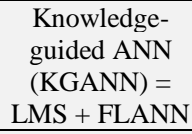 & $\begin{array}{c}\text { KGANN predicts } \\
\text { more accurately than } \\
\text { individual FLANN } \\
\text { and LMS }\end{array}$ \\
\hline $\begin{array}{c}\text { Rout et } \\
\text { al. }\end{array}$ & $\begin{array}{c}\text { USD } \\
\text { against } \\
\text { INR, GBP, } \\
\text { JPY } \\
\end{array}$ & $\begin{array}{c}\text { Recurrent } \\
\text { FLANN }\end{array}$ & $\begin{array}{l}\text { Proposed model pre- } \\
\text { dicts better than exist- } \\
\text { ing LMS and FLANN }\end{array}$ \\
\hline $\begin{array}{l}\text { Majhi et } \\
\text { al. }\end{array}$ & $\begin{array}{l}\text { USD to } \\
\text { INR, GBP, } \\
\text { and JPY }\end{array}$ & $\begin{array}{c}\text { Wilcoxon ANN } \\
\text { (WANN) and } \\
\text { WFLANN }\end{array}$ & $\begin{array}{c}\text { WANN and } \\
\text { WFLANN offer con- } \\
\text { sistent prediction and } \\
\text { WFLANN offer low } \\
\text { complexity }\end{array}$ \\
\hline
\end{tabular}

\subsection{RBFNN}

Due to the volatility of the financial market and several factors affecting the market decide, the forecasting of the financial market is still an active field of research. Every time researchers are trying to come up with efficient models that will give an accurate prediction of exchange rate movements. But, the FOREX market is so efficient in itself that it has become a bottleneck for the practitioners and econometricians. ANN has been used in various fields like monitoring, control, classification, and prediction and RBFNN is effective in prediction of financial time series. The use of RBF has been seen in the different field of research like speech recognition, radar target recognition, speaker identification etc. Then researchers in financial forecasting came with models with RBF. The hidden layer in RBFNN [47] differs from other neural networks. Each node here represents a data cluster with a predefined radius. Each node measures the distance from input vector to its center. Then with some basic function, the calculated distance is transformed and the result is given as an output from the node. As the output layer consists of one node so all the outputs of the previous layer are added and final output is produced.

Recently in 2017 Sun et al. [48] have applied RBFNN to forecast exchange rates of USD/EUR, USD/CHY and JPY/USD as RBFNN has the ability to detect the complex nonlinear relationships between dependent and independent variables. The learning algorithm used in the model uses a diverse dataset for training to adapt itself quickly to the new exchange data rate. The authors have used Generalized Regression Neural Networks (GRNNs) which is a kind of RBFNN that are often used for approximation and the results obtained were more accurate. Researchers [49] have compared the performance of heteroscedastic models, MLP and RBF network models where they found that among heteroscedastic models TGARCH and IGARCH are better than other models and in neural network models RBF do considerably better than MLP. But overall neural network models can be productively used to approximate the conditional volatility of exchanges rates (GBP/USD, DEM/USD, JPY/USD, INR/USD and EUR/USD). $\mathrm{Yu}$ et al. [50] in 2006 gave a reliability-based RBF ensemble model based on the research background that the results of ensemble network outperform the individual networks. The output of ensemble network is the combined outputs of several neural networks often aggregated which enhances the accuracy. Later in 2008 [47], they have employed a multistage nonlinear RBFNN ensemble forecasting model for forecasting the exchange rates of USD against GBP, EURO, JPY and DEM as feed-forward neural networks have one major drawback that their learning process is time-consuming. They have proposed a multistage process to develop an ensemble learning procedure because the existing ensemble learning models focused on ensemble strategy rather than a learning process. The results show that prediction using the multistage model gives better results. Forecasting of Financial market future values is a difficult task. Since EUR/USD H1 spot exchange rate has the highest traded volumes and highest amount of price change so Pavel Sedek in 2015 used RBFNN to forecast the exchange rate. He concluded from the results that it is appropriate for short-term ( 1 hour) prediction as it gives almost accurate result but it is not suitable for longer prediction.

RBFNN was used along with other techniques [51-55] where the proposed model provided more accuracy than using the only RBF for prediction of exchange rates. (Table 4)

Table 4: Findings of the model using RBFNN technique

\begin{tabular}{|c|c|c|c|}
\hline Authors & $\begin{array}{c}\text { Currency } \\
\text { used }\end{array}$ & Models used & Findings \\
\hline Kia et al. & EUR/USD & $\begin{array}{c}\text { Hybrid model (MLP + } \\
\text { RBF + ARIMA) }\end{array}$ & $\begin{array}{c}\text { Final result of } \\
\text { prediction is } \\
\text { better than } \\
\text { results of } \\
\text { individual mod- } \\
\text { els }\end{array}$ \\
\hline $\begin{array}{c}\text { Georgios } \\
\text { Serm- } \\
\text { pinis } \text { et } \\
\text { al. }\end{array}$ & $\begin{array}{c}\text { EUR/USD, } \\
\text { EUR/GBP, }\end{array}$ & $\begin{array}{c}\text { Adaptive RBF-Particle } \\
\text { Swam Optimization } \\
\text { (ARBF-PSO) }\end{array}$ & $\begin{array}{c}\text { ARBF-PSO } \\
\text { outperforms K } \\
\text { nearest neigh- } \\
\text { bor, ARIMA, } \\
\text { moving average } \\
\text { convergence/ } \\
\text { divergence } \\
\text { model }\end{array}$ \\
\hline $\begin{array}{c}\text { Ajit } \\
\text { Kumar } \\
\text { Rout } e t \\
a l .\end{array}$ & $\begin{array}{c}\text { USD, EU- } \\
\text { RO, Cana- } \\
\text { dian Dollar, } \\
\text { AUD, INR }\end{array}$ & $\begin{array}{c}\text { Functional Link and } \\
\text { Radial Basis function } \\
\text { ( FLRBF) and LM } \\
\text { learning algorithm }\end{array}$ & $\begin{array}{c}\text { FLRBF provide } \\
\text { significant } \\
\text { prediction accu- } \\
\text { racy in all ex- }\end{array}$ \\
\hline
\end{tabular}




\begin{tabular}{|c|c|c|c|}
\hline & & & change rates \\
\hline $\begin{array}{c}\text { Zhaochen } \\
\text { g Liu } \text { et } \\
\text { al. }\end{array}$ & $\begin{array}{c}\text { GBP/CNY } \\
\text { and } \\
\text { USD/CNY }\end{array}$ & $\begin{array}{c}\text { Architecture of } \\
\text { RBFNN, transfer } \\
\text { function, input and out } \\
\text { vectors was made with } \\
\text { many tests }\end{array}$ & $\begin{array}{c}\text { RBFNN fore- } \\
\text { caster has given } \\
\text { acceptable } \\
\text { performance } \\
\text { and it efficiently } \\
\text { managed the } \\
\text { uncertainties in } \\
\text { raw data }\end{array}$ \\
\hline $\begin{array}{c}\text { Minakhi } \\
\text { Rout } e t \\
\text { al. }\end{array}$ & USD/INR, & RSDFNPY & $\begin{array}{c}\text { RBFNN } \\
\text { outperforms } \\
\text { ULANN and } \\
\text { MLANN }\end{array}$ \\
\hline
\end{tabular}

\subsection{RNN}

The recurrent neuron in neural networks helps to accelerate the weights update and makes convergence faster. The greatest advantage of recurrent neurons is that they can remember the learning message which the networks cannot locate in local minima during the training process. The ability to memorize is due to a recurrence of similar patterns present in exchange rate time series. Kuan et al. [56] proposed a two-step procedure in 1995 to select feed-forward and recurrent networks and evaluate their performance in forecasting of exchange rates (USD against GBP, Canadian Dollar, DEM, JPY and Swiss Franc). Unfortunately, from the results, they could derive no conclusion as the forecasting results were mixed. ANNs have the ability to form their own internal models that's why they are mostly used for time series prediction. Back-propagation is a common method to train Feed-Forward Neural Networks. Due to some drawbacks of this method like short-term memory and the tendency of training algorithm to get stuck in local minima RNNs are being used which has the capability of overcoming short-term memory. RNN can store all previous input signals and thus independent on a number of look back steps. So back-propagation cannot be used to train these networks. Hence Erik Hulthenin 2004[57] used RNN trained with Evolutionary Algorithm (EA) to obtain a better series prediction. By using EA during the training the weights of a neuron, the architecture of connection and the size of the network are subjected to change. The EA used by Erik is modified Genetic Algorithm. He concluded that RNN provides better forecast than FFNN. A contradicting concept has been given by Divyapriya et al. [58] in 2013where they have compared the efficiency of the Backpropagation algorithm, HMM and RNN algorithm on forecasting of FOREX rates of EUR/USD. According to their study, they drew the conclusion that back-propagation algorithm gives more accuracy in prediction. Saini et al. [59] in 2016 compared the performances of FFNN and RNN for forecasting daily exchange rates of INR against four currencies: GBP, USD, EURO and JPY where they found that RNN gave better results than FFNN. The major drawback of RNN is it requires more memory for simulation than back-propagation and more connections. Asare et al. [60] in 2016 used RNN to increase the ability of GARCH models to forecast the volatility in return. They have taken monthly Naira/USD exchange rates from January 1991 to January 2016 and also inflation rate from January 1970 to December 2015. The hybrid model developed with simulated volatility series taking extra inputs proved to be the best model for forecasting both exchange rate and inflation rate.

Models using RNN for forecasting [61-64] predict the exchange rates better than other methods and researchers conclude that RNN can be successfully used for forecasting. (Table 5)
Table 5: Findings of the model using RNN technique

\begin{tabular}{|c|c|c|c|}
\hline Authors & $\begin{array}{c}\text { Currency } \\
\text { used }\end{array}$ & Models used & Findings \\
\hline Yuxi Ye & RMB/USD & $\begin{array}{c}\text { RNN: weight } \\
\text { update algorithm } \\
\text { was deduced by } \\
\text { gradient descent } \\
\text { method }\end{array}$ & $\begin{array}{c}\text { RNN perform } \\
\text { better than other } \\
\text { methods }\end{array}$ \\
\hline $\begin{array}{c}\text { Paolo } \\
\text { Tenti }\end{array}$ & DEM & $\begin{array}{c}\text { Three version of } \\
\text { RNN }\end{array}$ & $\begin{array}{c}\text { RNN can be suc- } \\
\text { cessfully applied } \\
\text { for forecasting }\end{array}$ \\
\hline $\begin{array}{c}\text { Kon- } \\
\text { dratenko } \\
\text { et al. }\end{array}$ & $\begin{array}{c}\text { USD against } \\
\text { JPY, Swiss } \\
\text { Franc, GBP } \\
\text { and EURO }\end{array}$ & $\begin{array}{c}\text { Data prepro- } \\
\text { cessing is done } \\
\text { with Kolmogorov- } \\
\text { Smirnov test and } \\
\text { R/S-analysis } \\
\text { before developing } \\
\text { RNN }\end{array}$ & $\begin{array}{c}\text { Neural network } \\
\text { predicts the in- } \\
\text { crement sign with } \\
\text { high probability }\end{array}$ \\
\hline $\begin{array}{c}\text { Mehreen } \\
\text { Rehman } \\
\text { et al. }\end{array}$ & $\begin{array}{c}\text { AUD against } \\
\text { IDR, JPY, } \\
\text { CAD, NZD, } \\
\text { KRW }\end{array}$ & $\begin{array}{c}\text { Recurrent Carte- } \\
\text { sian General } \\
\text { Programming } \\
\text { evolved ANN } \\
\text { (RCGPANN) }\end{array}$ & $\begin{array}{c}\text { RCGPANN } \\
\text { proved to be com- } \\
\text { putationally effi- } \\
\text { cient and accurate } \\
\text { model }\end{array}$ \\
\hline
\end{tabular}

\section{Conclusion}

It is evident from the review that ANN has proven to be the effective model till date. The ability of ANN to handle complex data, not considering any assumptions, approximate continuous measurable data, and adaptive nature has popularized the use of ANN in every field of research. Many researchers have compared ANN with all other models and found that ANN proved to beat them in terms of accuracy. ANN has given impeccable results in spite of various factors affecting the volatile financial market and justified very well that it can be used in exchange rate forecasting. Now researchers are more focused on enhancing the accuracy of forecasting by developing a model using evolutionary optimization learning techniques.

\section{References}

[1] Largest trading hubs https://www.investopedia.com/terms/f/foreign-exchange.asp

[2] Foreign Exchange Market https://en.wikipedia.org/wiki/Foreign_exchange_market

[3] Foreign Exchange https://en.wikipedia.org/wiki/Foreign_exchange_market

[4] Richard A. Meese, and Kenneth Rogoff. "Empirical exchange rate models of the seventies: Do they fit out of sample?." Journal of international economics 14, no. 1-2 (1983): 3-24.

[5] Don Alexander and Lee R. Thomas III. "Monetary/Asset models of Exchange Rate Determination: How well have they Performed in the 1980's?." International Journal of Forecasting 3, no. 1 (1987): 53-64.

[6] Efficient Market https://en.wikipedia.org/wiki/Efficientmarket_hypothesis\#cite_note-7

[7] Francesco Lisi and Rosa A. Schiavo. "A comparison between neural networks and chaotic models for exchange rate prediction." Computational Statistics \& Data Analysis 30, no. 1 (1999): $87-102$.

[8] Huseyin Ince and Theodore B. Trafalis. "A hybrid model for exchange rate prediction." Decision Support Systems 42, no. 2 (2006): 1054-1062.

[9] Robert F. Engle. "Autoregressive conditional heteroscedasticity with estimates of the variance of United Kingdom inflation." Econometrica: Journal of the Econometric Society (1982): 987-1007.

[10] Tim Bollerslev. "Generalized autoregressive conditional heteroskedasticity." Journal of Econometrics 31, no. 3 (1986): 307-327.

[11]Erik W. Tyree and J. A. Long. "Forecasting currency exchange rates: neural networks and the random walk model." In City University Working Paper, Proceedings of the Third International Conference on Artificial Intelligence Applications. 1995. 
[12]Mona R. El Shazly and Hassan E. El Shazly. "Comparing the forecasting performance of neural networks and forward exchange rates." Journal of Multinational Financial Management 7 , no. 4 (1997): 345-356.

[13] JingtaoYao,Hean-Lee Poh, and Teo Jasic. "Foreign exchange rates forecasting with neural networks." In International Conference on Neural Information Processing (Hong Kong. 1996.

[14]Christian Dunis and Mark Williams. "Modelling and trading the EUR/USD exchange rate: Do neural network models perform better?." Derivatives use, trading and regulation 8, no. 3 (2002): 211-239.

[15] Adewole Adetunji Philip, Akinwale Adio Taofiki, and Akintomide Ayo Bidemi. "Artificial neural network model for forecasting foreign exchange rate." World of Computer Science and Information Technology Journal 1, no. 3 (2011): 110-118.

[16] V. Ravi, Ramanuj Lal, and N. Raj Kiran. "Foreign exchange rate prediction using Computational Intelligence Methods." International Journal of Computer Information Systems and Industrial Management Applications 4 (2012): 659-670.

[17] Christian L. Dunis, Jason Laws, and Ulrike Schilling. "Currency trading in volatile markets: Did neural networks outperform for the EUR/USD during the financial crisis 2007-2009?." Journal of Derivatives \& Hedge Funds 18, no. 1 (2012): 2-41.

[18] Olcay Erdogan and Ali Goksu. "Forecasting Euro and Turkish Lira Exchange Rates with Artificial Neural Networks (ANN)." International Journal of Academic Research in Accounting, Finance and Management Sciences 4, no. 4 (2014): 307-316.

[19] Nathan D' Lima and Shamsuddin S. Khan. "FOREX rate prediction using ANN and ANFIS."

[20] Galeshchuk, Svitlana. "Neural networks performance in exchange rate prediction." Neurocomputing 172 (2016): 446-452.

[21] Ashok K Nag and Amit Mitra. "Forecasting daily foreign exchange rates using genetically optimized neural networks." Journal of Forecasting 21, no. 7 (2002): 501-511.

[22] He Ni and Hujun Yin. "Exchange rate prediction using hybrid neural networks and trading indicators." Neurocomputing 72, no. 13 (2009): 2815-2823.

[23] Chakradhara Panda and V. Narasimhan. "Forecasting exchange rate better with artificial neural network." Journal of Policy Modeling 29, no. 2 (2007): 227-236

[24] Gioqinang Zhang and Michael Y. Hu. "Neural network forecasting of the British pound/US dollar exchange rate." Omega 26, no. 4 (1998): 495-506.

[25] J. C. Carney, and Padraig Cunningham. "Neural networks and currency exchange rate prediction." Foresight Business Journal (1996).

[26] Joarder Kamruzzaman and Ruhul A. Sarker. "ANN-based forecasting of foreign currency exchange rates." Neural Information Processing-Letters and Reviews 3, no. 2 (2004): 49-58.

[27] Suresh Kumar Sharma and Vinod Sharma. "Proficient Prophecy of Foreign Exchange Rate using Artificial Neural Network: A Case of USD to INR." International Journal of Computer Applications 43, no. 1 (2012).

[28]Li Meng and Yang Sun. "Research on Automated Forex Trading System Based on BP Neural Network." In Advanced materials re search, vol. 753, pp. 3080-3083. Trans Tech Publications, 2013.

[29] V. Lavanya, and M. Parveentaj. "Foreign currency exchange rate (FOREX) using neural network." International Journal of Science and Research 2, no. 10 (2013): 174-177.

[30] S. Kumar Chandar, M. Sumathi, and S. N. Sivanandam. "Forecasting of Foreign Currency Exchange Rate Using Neural Network."

[31] Gour Sundar Mitra Thakur, Rupak Bhattacharyya, and Seema Sarkar Mondal. "Artificial neural network based model for forecasting of inflation in India." Fuzzy Information and Engineering 8, no. 1 (2016): 87-100.

[32] Murthy, KV Bhanu. "Forecasting Foreign Exchange Rate during Crisis-A Neural Network Approach."

[33] Chen, Joseph C., and Naga Hrushikesh R. Narala. "Forecasting Currency Exchange Rates via Feedforward Backpropagation Neural Network." (2017).

[34] Sun Ye. "RMB exchange rate forecast approach based on BP neural network." Physics Procedia 33 (2012): 287-293.

[35] Rudra P Pradhan and Rajesh Kumar. "Forecasting exchange rate in India: An application of artificial neural network model." Journal of Mathematics Research 2, no. 4 (2010): 111.

[36]Lean Yu, Shouyang Wang, and Kin Keung Lai. "Hybridizing BPNN and Exponential Smoothing for Foreign Exchange Rate Prediction." Foreign-Exchange-Rate Forecasting With Artificial Neural Networks (2007): 121-131.
[37] S. Kumar Chandar, M. Sumathi, and S. N. Sivanandam. "Neural network based forecasting of foreign currency exchange rates." International Journal on Computer Science and Engineering 6, no. 6 (2014): 202.

[38] Ritanjali Majhi, Ganapati Panda, and Gadadhar Sahoo. "Efficient prediction of exchange rates with low complexity artificial neural network models." Expert systems with applications 36, no. 1 (2009): 181-189.

[39] Yohhan Pao. "Adaptive pattern recognition and neural networks." (1989).

[40] K. K. Sahu, G. R. Biswal, P. K. Sahu, S. R. Sahu, and H. S. Behera. "A CRO based FLANN for forecasting foreign exchange rates using FLANN." In Computational Intelligence in Data MiningVolume 1, pp. 647-664. Springer, New Delhi, 2015.

[41] Jagdish C. Patra, Nguyen C. Thanh, and Pramod K. Meher. "Computationally efficient FLANN-based intelligent stock price prediction system." In Neural Networks, 2009. IJCNN 2009. International Joint Conference on, pp. 2431-2438. IEEE, 2009.

[42] C. M Anish and Babita Majhi. "Net asset value prediction using FLANN model." International Journal of Science and Research (IJSR 4, no. 2 (2015): 2222-2227.

[43] Xian Hua, Defu Zhang, and Stephen CH Leung. "Exchange rate prediction through ANN Based on Kernel Regression." In Business Intelligence and Financial Engineering (BIFE), 2010 Third International Conference on, pp. 39-43. IEEE, 2010.

[44] Pradyot Ranjan Jena, Ritanjali Majhi, and Babita Majhi. "Development and performance evaluation of a novel knowledge guided artificial neural network (KGANN) model for exchange rate prediction." Journal of King Saud University-Computer and Information Sciences 27, no. 4 (2015): 450-457.

[45]A. ROUT. "Efficient Forecasting of Exchange rates with Recurrent FLANN. IOSR." Journal of Computer Engineering 13, no. 6 (2013): 21-28.

[46] Babita Majhi, Minakhi Rout, Ritanjali Majhi, Ganapati Panda, and Peter J. Fleming. "New robust forecasting models for exchange rates prediction." Expert Systems with Applications39, no. 16 (2012): 12658-12670.

[47]Lean Yu, Kin Keung Lai, and Shouyang Wang. "Multistage RBF neural network ensemble learning for exchange rates forecasting." Neurocomputing 71, no. 16-18 (2008): 3295-3302.

[48] Ai Sun and Jui-Fang Chang. "Application Of Radial Basis Function Neural Network To Predict Exchange Rate With Financial Time Series." International Journal on Smart Sensing and Intelligent Systems 10, no. 2 (2017): 308-326.

[49] A. K. Dhamija, and V. K. Bhalla. "Financial time series forecasting: comparison of neural networks and ARCH models." International Research Journal of Finance and Economics 49 (2010): 185-202.

[50]Lean Yu, Wei Huang, Kin Keung Lai, and Shouyang Wang. "A reliability-based RBF network ensemble model for foreign exchange rates predication." In International Conference on Neural Information Processing, pp. 380-389. Springer, Berlin, Heidelberg, 2006.

[51] Arash Negahdari Kia, Mohammad Fathian, and M. R. Gholamian. "Using MLP and RBF Neural Networks to Improve the Prediction of Exchange Rate Time Series with ARIMA." International Journal of Information and Electronics Engineering 2, no. 4 (2012): 543.

[52] G. Sermpinis, K. Theofilatos, A. Karathanasopoulos, E.F. Georgopoulos and C. Dunis, 2013. Forecasting foreign exchange rates with adaptive neural networks using radial-basis functions and particle swarm optimization. European Journal of Operational Research, 225(3), pp.528-540.

[53] Ajit Kumar Rout and P. K. Dash. "Forecasting foreign exchange rates using hybrid functional link RBF neural network and Levenberg-Marquardt learning algorithm." Intelligent Decision Technologies 10, no. 3 (2016): 299-313

[54]Zhaocheng Liu, Ziran Zheng, Xiyu Liu, and Gongxi Wang. "Modelling and Prediction of the CNY Exchange Rate Using RBF Neural Network." In Business Intelligence and Financial Engineering, 2009. BIFE'09. International Conference on, pp. 38 41. IEEE, 2009.

[55] Minakhi Rout, Babita Majhi, and Usha Manasi Mohapatra. "Efficient long range prediction of exchange rates using Radial Basis Function Neural Network models." In Advances in Engineering, Science and Management (ICAESM), 2012 International Conference on, pp. 530-535. IEEE, 2012.

[56] Chung-Ming Kuan and Tung Liu. "Forecasting exchange rates using feedforward and recurrent neural networks." Journal of applied econometrics 10, no. 4 (1995): 347-364 
[57] Erik. Hulthen. Improving time series prediction using recurrent neural networks and evolutionary algorithms. Chalmers tekniska högsk, 2004.

[58] R. Divyapriya, R. Manicka Chezhian. “Accurate Forecasting Prediction of Foreign Exchange Rates Using Neural Network Algorithms: A Study", IJCSMC, Vol. 2, Issue. 7, pp. 344-349, 2013.

[59] Sanju Singh Saini, Omkar Parkhe, and T. D. Khadtare. "Analysis of Feedforward and Recurrent Neural Network in Forecasting Foreign Exchange Rate." Imperial Journal of Interdisciplinary Research 2, no. 6 (2016).

[60] Asare, B. K., S. U. Gulumbe, M. Abubakar, and S. Suleiman. "Volatility Forecasting: An application of a Recurrent Dynamic Neural Networks in Nigeria."

[61] Yuxi Ye. "Study on Exchange Rate Forecasting Using Recurrent Neural Networks." International Journal of Economics, Finance and Management Sciences 5, no. 6 (2017): 300.

[62] Paolo Tenti. "Forecasting Foreign Exchange Rates Using Recurrent Neural Networks", Applied Artificial Intelligence, Vol. 10, Issue. 6, pp. 567-582, 1996.

[63] V. V. Kondratenko, and Yu A. Kuperin. "Using recurrent neural networks to forecasting of forex." arXiv preprint condmat/0304469 (2003).

[64] Mehreen Rehman, Gul Muhammad Khan, and Sahibzada Ali Mahmud. "Foreign currency exchange rates prediction using cgp and recurrent neural network." IERI Procedia 10 (2014): 239-244. 